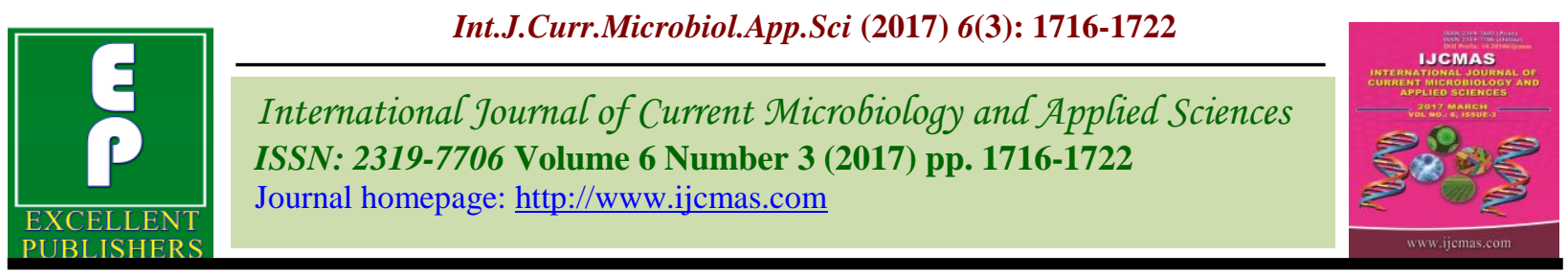

Original Research Article

https://doi.org/10.20546/ijcmas.2017.603.197

\title{
Histomorphology and Scanning Electron Microscopy of the Lingual Tonsil in Goats
}

\author{
V.R. Indu*, K.M. Lucy, N. Ashok and S. Maya \\ Department of Veterinary Anatomy, College of Veterinary and Animal Sciences, \\ Mannuthy- 680651, India \\ *Corresponding author
}

\begin{abstract}
A B S T R A C T
Keywords

Goats, Histology,

Morphology,

Lingual tonsil,

Scanning Electron

Microscopy.

Article Info

Accepted:

24 February 2017

Available Online:

10 March 2017

A study was conducted on the lingual tonsil of six male crossbred goats of six months of age. The lingual tonsil could not be identified macroscopically but in histological sections aggregations of lymphocytes were seen within the core of vallate papillae present in the root of tongue. The stratified squamous keratinized surface epithelium was composed of strata basale, spinosum and corneum, arranged in twelve to fifteen layers and measured $720.35 \pm 13.20 \mu \mathrm{m}$. At the region of small crypts, the surface epithelium presented fewer cell layers and was called reticular epithelium or lymphoepithelium. It measured $263.48 \pm 5.25 \mu \mathrm{m}$ in height and was associated with lymphoid tissue. Hassall's corpuscles were occasionally detected towards the outer surface epithelium. Propria-submucosa in the core of vallate papillae presented lymphoid tissue which was devoid of any lymphoid nodules. Lymphoid cell aggregations were also noticed in between glandular acini, striated muscles and around the ducts of mucous glands which opened towards the surface epithelium of the vallate papillae. Scanning electron microscopy of the vallate papillae revealed an elevated structure surrounded by deep narrow crypt and was covered by squamous epithelium with dense microplicae and distinct cell junctions. Large numbers of lymphocytes were seen within the propria-submucosa of the vallate papillae.
\end{abstract}

\section{Introduction}

According to Nickel et al., (1979), diffuse lymphocytic accumulations in the tongue of domestic animals were grouped under tonsillar tissue. The lingual tonsil was limited to the root of the tongue in sheeps (Cocquyt $e t$ al., 2005), horses (Kumar and Timoney, 2005b) and bovines (Cocquyt et al., 2008). This tonsil is involved in processing antigens because of its close association with diffuse lymphoid tissue and high endothelial venules, making it the first line of defense. A perusal of literature revealed only few studies on the lingual tonsils in goats and hence the present work was undertaken.

\section{Materials and Methods}

Six crossbred male goats of six months of age were used for the present study. From the head, tissue pieces were collected from the tongue and fixed in 10 per cent neutral buffered formalin. The materials were processed routinely to obtain $5-6 \mu \mathrm{m}$ thick serial paraffin sections. The sections were stained by Haematoxylin and Eosin (Luna, 1968), Gomori's rapid one step trichrome method for collagen fibres (Luna, 1968), Verhoeff's method for elastic fibres (Singh and Sulochana, 1996), Gordon and Sweet's method for reticular fibres (Bancroft and 
Gamble, 2003) and Unna's method for mast cells (Luna, 1968).

For scanning electron microscopy, samples of lingual tonsils were fixed in 2.5 per cent gluteraldehyde in $0.1 \mathrm{M}$ phosphate buffer (PBS) (pH 7.2) for $24 \mathrm{~h}$ at $4^{\circ} \mathrm{C}$ and post fixed in two per cent aqueous osmium tetroxide for four hours. Thereafter the samples were processed and scanned under Scanning Electron Microscope (SEM-Model: JEOLJSM 5600) at required magnifications at Ruska Labs, College of Veterinary Science, Rajendranagar, Hyderabad, Andhra Pradesh.

\section{Results and Discussion}

The present study revealed that though the lingual tonsil was not visible macroscopically, in histological sections lymphoid aggregations of the lingual tonsil were present within the connective tissue core of the vallate papillae that were situated at the root of the tongue (Fig. 1). Small lymphoid aggregations were also noticed surrounding the ducts of salivary glands that opened on the surface of the lingual root and in between the lingual muscles and salivary glands in vallate papillae (Fig. 2). Similar observations were made in sheep by Casteleyn et al., (2007). However, Kumar and Timoney (2005a) reported that the lingual tonsils were seen at the root of the tongue within the rounded elevations, folds and crypts in horse. Cocquyt et al., (2008) demonstrated that numerous small openings were seen on the lingual root surface caudal to vallate papillae representing the lingual tonsil in bovines.

Outer surface of the lingual tonsil was covered by keratinised stratified squamous epithelium. It presented an irregular outer surface and an unevenly placed deeper surface with interpapillary pegs. The epithelium was composed of strata basale, spinosum and corneum (Fig. 1) and measured
$720.35 \pm 13.20 \mu \mathrm{m}$ in height. Number of cell layers in the surface epithelium ranged from twelve to fifteen. The columnar cells of stratum basale presented oval to elongated nuclei that was strongly basophilic and the cytoplasm was slightly basophilic. In the stratum spinosum, six to twelve layers of irregularly polyhedral cells were seen with lightly basophilic nuclei of different shapes. The stratum corneum consisted of squamous cells with eosinophilic and finely granular cytoplasm and irregular pyknotic nuclei. The signs of degeneration in the nuclei were more towards the free surface of the epithelium. Casteleyn et al., (2010) also made similar observations in the lingual tonsils of sheep. The presence of keratohyaline granules in the stratum superficiale was reported in the nonkeratinized epithelium of lingual tonsil in horse by Kumar and Timoney (2005b) and in goat by Kumar and Kumar (2005).

A few small crypts were seen where the surface epithelium was modified into reticular epithelium or lymphoepithelium and was associated with lymphoid tissue (Fig. 3). The crypts increased the epithelial surface area in contact with the tonsillar parenchyma and thus, ingested material might get close proximity with the significantly larger volume of lymphoid tissue. This indicated a specific functional relationship between environment of oral cavity and tonsillar lympho-epithelial tissue (Koburg, 1967). The height of the reticular epithelium was $263.48 \pm 5.25 \mu \mathrm{m}$ and presented fewer cell layers. The interpapillary pegs were also absent. Non-epithelial cells like lymphocytes, macrophages and plasma cells were seen. Lamellated structures resembling Hassall's corpuscles were occasionally detected towards the outer surface epithelium. The stratum basale was heavily infiltrated with lymphoid cells and numerous blood capillaries. These observations concur with the earlier reports of Kumar and Timoney (2005b) in horse and 
Kumar and Kumar (2005) in goat. Degeneration of epithelial cells and formation of epithelial corpuscles was associated with reticulation of tonsillar epithelium (Perry and Slipka, 1993).

Propria-submucosa was characterized by densely packed collagen and elastic fibres. In the core of vallate papillae a small meshwork of reticular fibres was seen with a few lymphoid cells (Fig. 4). The lymphoid tissue was devoid of any lymphoid nodules. These observations agreed with the findings of Kumar and Kumar (2005) in goats. Contrarily, Kumar and Timoney (2005b) in horse and Rebmann and Gasse (2008) in ox observed that the lymphoid tissue was distributed in the form of lymphoid follicles stacked one above the other. As reported by Casteleyn et al., (2007) in sheep, the lingual tonsil was not encapsulated.

Fig.1 C.S. of vallate papillae showing lymphoid aggregations (H\&Ex200)

1. Stratum corneum

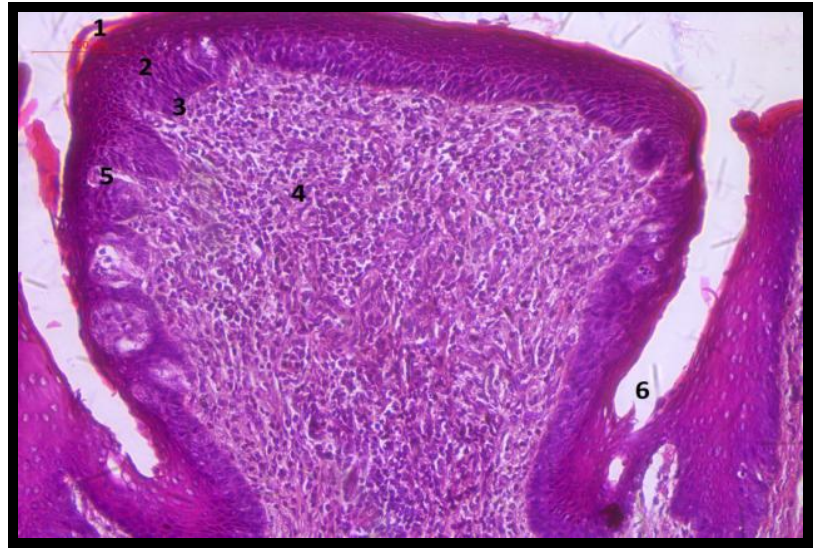

2. Stratum spinosum

3. Stratum basale

4. Lymphocytes in connective tissue core

5. Taste bud

6. Crypt

Fig.2 C.S. of root of tongue showing lymphoid aggregations (H\&Ex100)

1. Surface epithelium

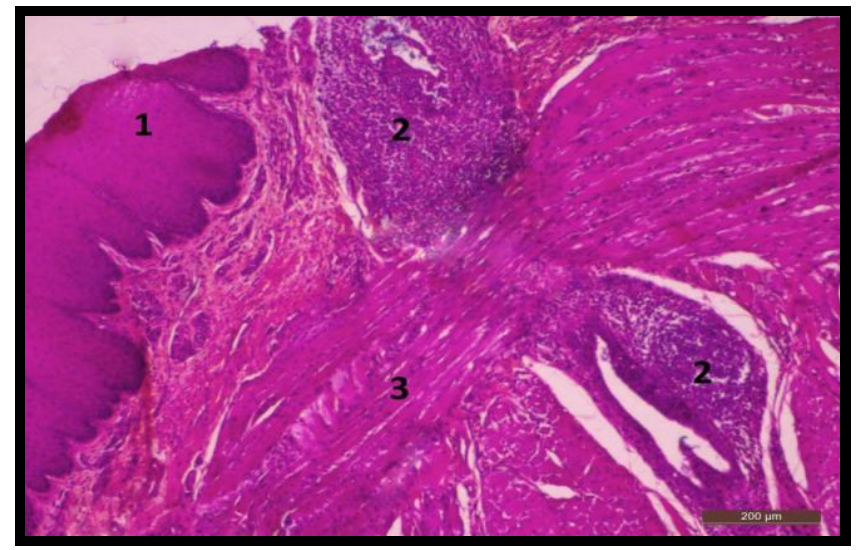

2. Lymphoid aggregations

3. Skeletal muscles 
Fig.3 C.S. of lingual tonsil showing reticular epithelium. Gomori's one step trichrome x 200

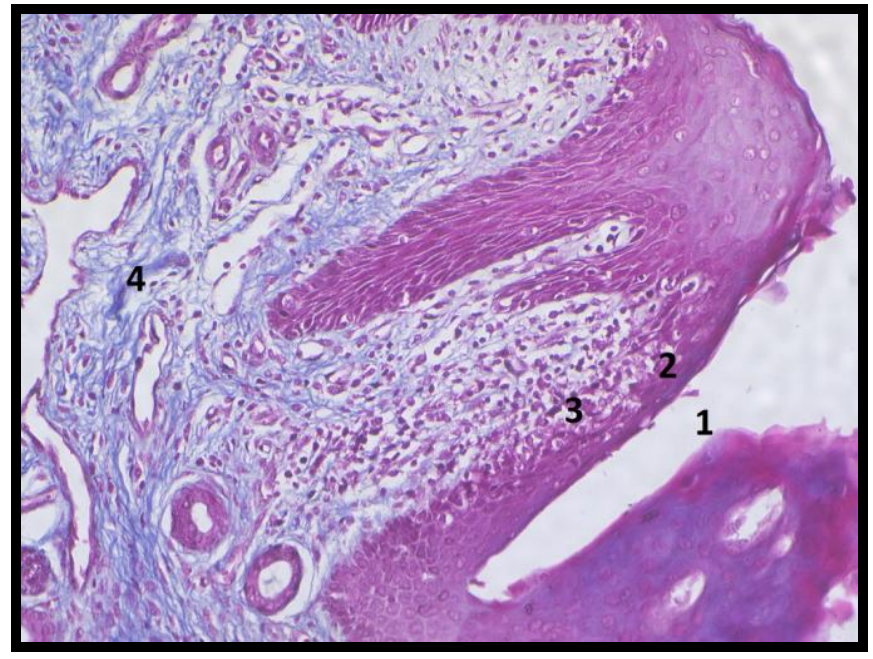

1. Crypt

2. Reticular epithelium

3. Lymphocytes

4. Collagen fibres

Fig.4 C.S. of lingual tonsil showing reticular fibers (4 month). Gordon and Sweet silver impregnation method X 400

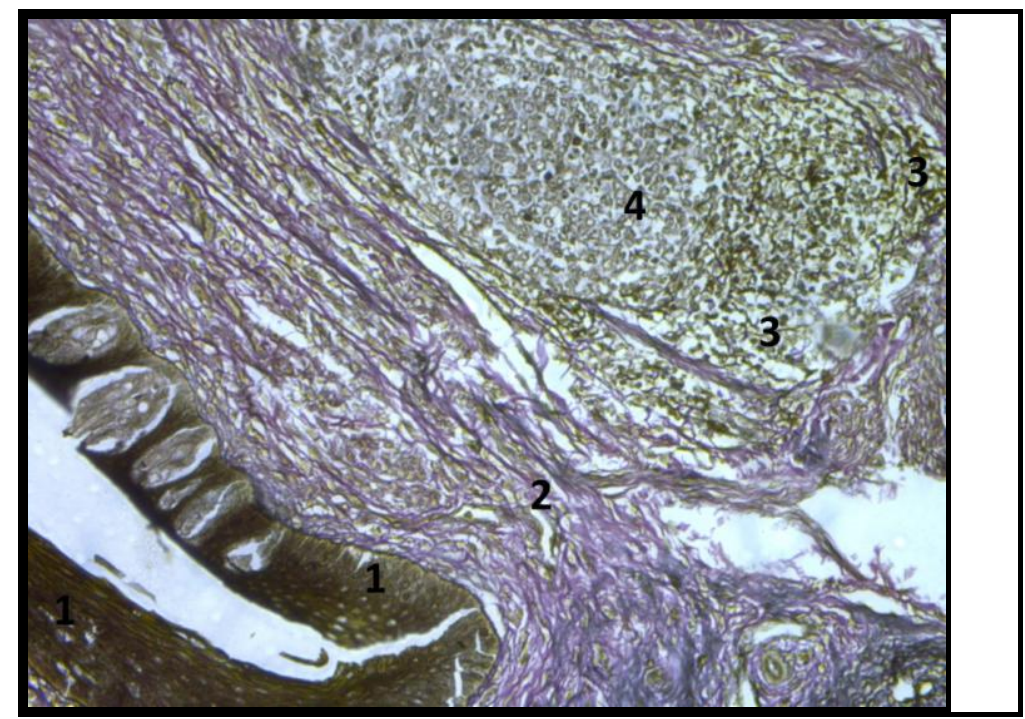

1. Stratified squamous epithelium

2. Connective tissue

3. Reticular fibres

4. Lymphocytes 
Fig.5 Ultramicroscopy of lingual tonsil showing squamous cells. SEM x 8000

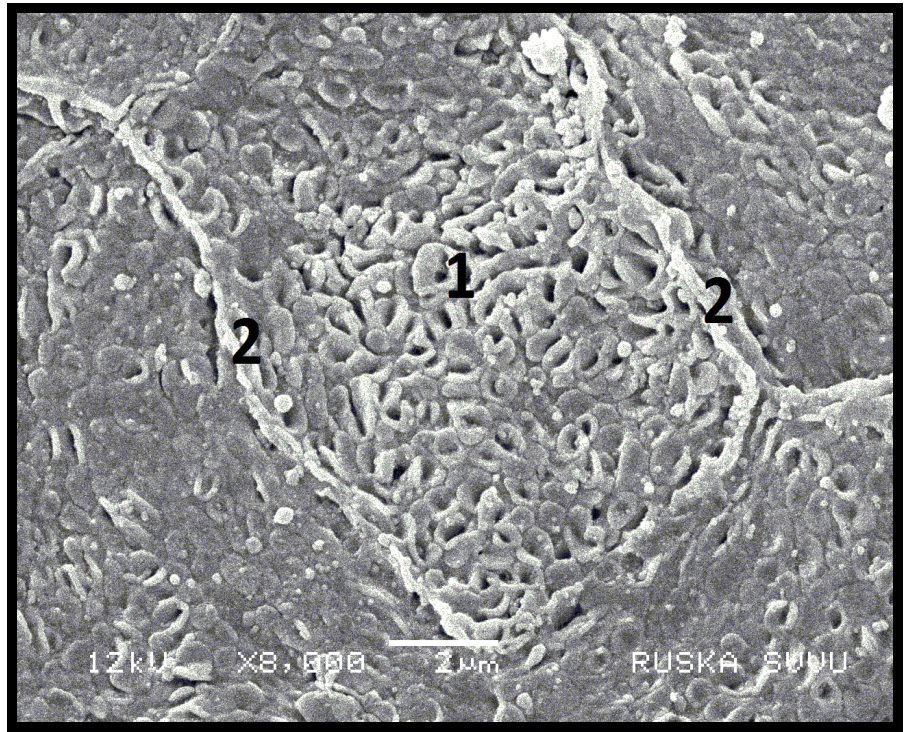

1. Cells covered by densely packed microplicae

2. Cell junctions

Fig.6 Ultramicroscopy of lingual tonsil showing lymphocytes in the propria submucosa. SEM x 800

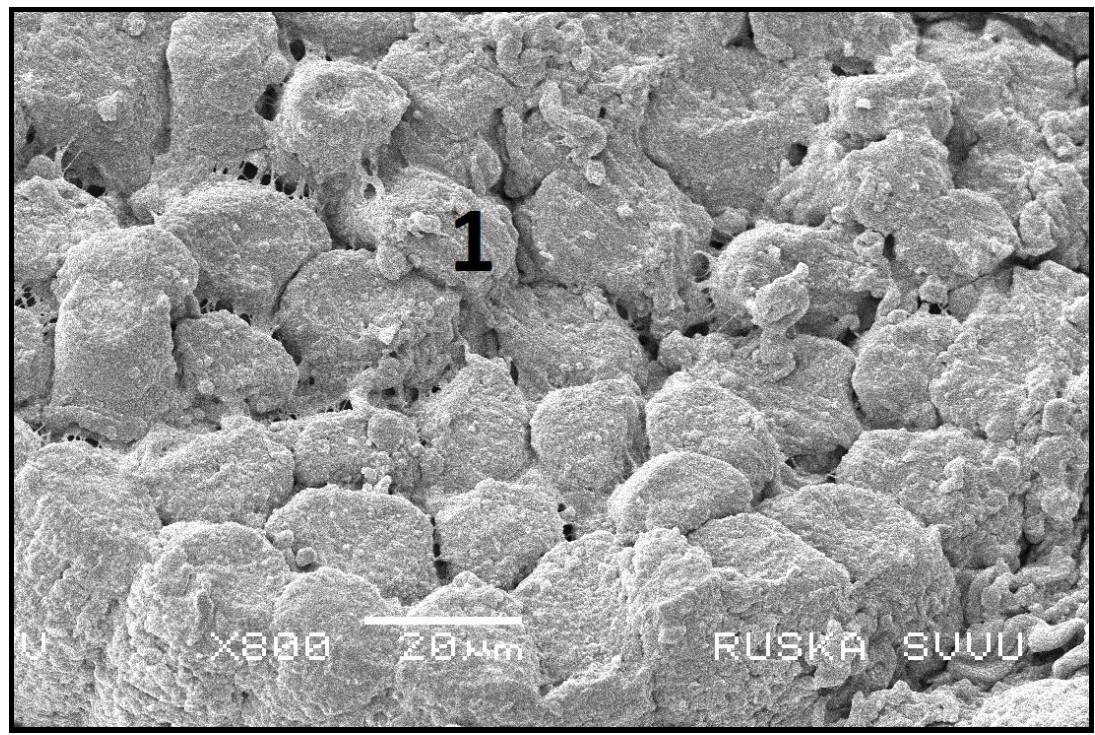

Numerous fine blood capillaries were also noted in the lamina propria. HEVs were seen near the lymphoid tissue. Ruskell (1995) found that transfer of lymphocytes from the blood to the tonsils was essential for their immunological capability but since the tonsils lacked afferent lymphatics naive lymphocytes entered through specific blood vessels known as HEVs.

Deeper part of propria-submucosa presented both serous and mucous glands, bundles of skeletal muscle, nerve bundles and adipose tissue. Lymphoid cell aggregations were also 
noticed in between glandular acini. The intraglandular and interglandular ducts were lined by simple to stratified cuboidal epithelium of two cell thickness. Ducts of mucous glands which opened towards the surface epithelium were surrounded by dense lymphoid tissue. Lymphoid aggregations were also seen in between bundles of striated muscles (Fig. 2). These observations agreed with the findings of Kumar and Timoney (2005b) in horse and Kumar and Kumar (2005) in goats.

Scanning Electron Microscopy (SEM) of the vallate papillae revealed an elevated structure surrounded by deep narrow crypt and was covered by squamous epithelium with few exfoliated cells. The squamous cells were covered by densely packed microplicae. The cell junctions were distinct due to the dense uniform arrangement of microplicae (Fig. 5). Kumar and Kumar (2005) and Casteleyn et al., (2010) made similar observations on the morphology of the tonsils in goats and sheep, respectively. Large numbers of lymphocytes were seen in the propria submucosa (Fig. 6). Though macroscopically visible lingual tonsils as seen in bovine were not seen in goats, the typical distribution and abundance of lymphoid tissue at the root of the tongue within the vallate papillae than in other parts of the tongue, justified the use of the term "lingual tonsil'" as suggested by Cocquyt et al., (2008) in sheep.

It was concluded that in goats, the lingual tonsils showed abundant lymphoid tissue within the vallate papillae in its connective tissue core and also in between the lingual muscles and glandular acini. Lymphoid tissue was also seen surrounding the ducts of mucous glands which opened towards the surface epithelium of the lingual root. The lingual tonsils helped to augment immunological protection at the entrance of the digestive system.

\section{References}

Bancroft, J.D. and Gamble, M. 2003. Theory and Practice of Histological Techniques. $\quad\left(5^{\text {th }}\right.$ Ed.). Churchill Livingstone, New York, 796p.

Casteleyn, C., Broeck, V.W. and Simoens, P. 2007. Histological characteristics and stereological volume assessment of the ovine tonsils. Vet. Immunol. Immunopathol., 120: 124-135.

Casteleyn, C., Cornelissen, M., Simoens, P. and Broeck, V.W. 2010. Ultramicroscopic examination of the ovine tonsillar epithelia. Anatomical Res., 293: 879-888.

Cocquyt, G., Baten, T., Simoens, P. and Broeck, W.V.D. 2005. Anatomical localisation and histology of the ovine tonsils. Vet. Immunol. Immunopathol., 107: 79-86.

Cocquyt, G., Simoens, P., Muylle, S. and Broeck, W.V.D. 2008. Anatomical and histological aspects of the bovine lingual tonsil. Res. Vet. Sci., 84: 166173.

Koburg, E. 1967. Cell production and migration in the tonsil. In: Cottier, H., Odartchenko, N.,

Schindler, R. (eds.), Germinal Centers in Immune Responses. Springer Verlag, Berlin, pp. 176-182.

Perry, M.E. and Slipka, J. 1993. Formation of the tonsillar corpuscle. Functional Developmental Morphol., 3: 165-168.

Rebmann, S. and Gasse, H. 2008. Bovine lingual tonsil: Histomorphological characteristics with special reference to the follicular dendritic cells. Anatomia Histologia Embryologia, 37: 430-434.

Ruskell, G.L. 1995. Organization and cytology of lymphoid tissue in the cynomolgus monkey conjunctiva. Anatomical Record, 243: 153-164.

Kumar, P. and Kumar, P. 2005. Light and scanning electron microscopic studies 
on lingual tonsil of goat. Haryana Veterinarian. 44: 13-16.

Kumar, P. and Timoney, J.F. 2005a. Histology, immunohistochemistry and ultrastructure of the equine palatine tonsil. Anatomia Histologia Embryologia, 34: 192-198.

Kumar, P. and Timoney, J.F. $2005 \mathrm{~b}$. Histology and ultrastructure of the equine lingual tonsil. I. crypt epithelium and associated structures. Anatomia Histologia Embryologia, 34: 27-33.

Luna, L.G. 1968. Manual of Histological
Staining Methods of the Armed Forces Institute of Pathology. ( $3^{\text {rd }} \mathrm{Ed}$.). Mc Graw-Hill Book Company, New York, 258p.

Nickel, R., Schummer, A. and Seiferle, E. 1979. The Viscera of the Domestic Animals. Verlag Paul Parey, Berlin. $2202 p$.

Singh, U.B. and Sulochana, S. 1996. Handbook of Histological and Histochemical Techniques. Premier Publishing House, Hyderabad, 111p.

\section{How to cite this article:}

Indu, V.R., K.M. Lucy, N. Ashok and Maya, S. 2017. Histomorphology and Scanning Electron Microscopy of the Lingual Tonsil in Goats. Int.J.Curr.Microbiol.App.Sci. 6(3): 1716-1722. doi: https://doi.org/10.20546/ijcmas.2017.603.197 